\title{
The Effectiveness of Cognitive Reframing Therapy and Motivational Interviewing on the Promotion of COVID-19 Awareness and Health-Behaviours in Ibadan
}

\author{
Dr. Oluwaseun Emmanuel Omopo \\ Department of Psychology, Faculty of Nursing and Health Sciences, IICSE University, Wilmington, Delaware, USA
}

\begin{abstract}
This study investigated the effects of cognitive reframing therapy and motivational interviewing on the promotion of COVID-19 awareness and health-behaviours in Ibadan, Nigeria. Five (5) null hypotheses guided the work. Quasiexperimental design involving pre-test, post-test, control group with two experimental and one control groups was adopted for the study. The population of the study comprised sixty (60) identified/observed participants with non-adherence to COVID19 preventive behaviours: irregular disuse of face mask, lack of regular handwashing, risk behaviours/exposure to close contacts, lack of social and physical distance. The purposive sampling procedure was used in selecting 60 samples and was grouped into treatments and control. A self-report questionnaire on COVID19 knowledge and adherence to safety measures developed by Hanawi, Angawi, Alshareef, Ameerah et al (2020) was utilized in this study. The ANCOVA statistical tool was used to test five hypotheses raised at 0.005 alpha level of significance. The findings revealed that both cognitive reframing therapy and motivational interviewing are effective in the promotion of COVID-19 awareness and health-behaviours of participants. Comparing the two modalities, both were effective $(p=0.821)$ in promoting COVID-19 awareness and health-behaviours among residents of Ibadan, Nigeria. The result found no significant differential effect of cognitive reframing therapy in the promotion of COVID-19 awareness and health-behaviours of Ibadan residents $(p=0.379)$, no significant differential effect of motivational interviewing in the promotion of COVID-19 awareness and health-behaviours of Ibadan residents $(p=0.391)$. The researcher recommended that the government should endeavour to engage the public more extensively using a much closer medium rather than through the media. It was also recommended that urgent psychological facilities, equipped with seasoned professionals be structured in local government areas towards effective management of psychological well-being, resistant attitudes to preventive measures, and general healthbehaviour advancement. The study furthered to recommend that authorities should consider providing enough palliatives to the most vulnerable population and subsidize crumbled businesses for effective recovery and adjustment.
\end{abstract}

Keywords: COVID-19, COVID-19 awareness, health-related behaviours, cognitive reframing therapy, motivation interviewing.

\section{INTRODUCTION}

$\mathrm{C}$ Coronavirus disease 2019 (COVID-19) according to the World Health Organization (2020) has been perceived as an attacking irresistible viral sickness brought about by extreme intense respiratory disorder coronavirus 2 (SARSCoV-2), Due to the quickly expanding infectious nature of the coronavirus, which is overpowering basic healthcare and frontline health staffs and the chance of transmission by asymptomatic transporters, governments around the globe, shut their environment, declared partial or total lockdown, limit developments, enforce social separation and facemask wearing regulations (Zaka, Shamloo and Fiorente 2020). The complete number of infected people worldwide as at August 15,2020 had ascended to $21,503,297$ with more than 766,334 deaths across 213 nations of the world (Worldometers Coronavirus Update, 2020). In particular, every African nation have been hit with the pandemic coming about to 874,036 infected people and 18,498 deaths, and there are 48,445 affirmed cases and 973deaths in Nigeria as at 15 August, 2020 (Nigeria Centre for Disease Control, 2020). According to Omopo, Dada and Adebayo-Oke (2020), prudent conducts (e.g., self-isolation, shutting down of schools and work places) and precautionary mode (e.g., regular hand washing with cleanser, social distancing, and so on) of human contact practices are distinguished as contamination control measures which may help reduce the spread of infections. To accomplish the fruitful execution of such measures suggested by health specialists, the consciousness and readiness of the public play a significant and unequivocal role. Be that as it may, it is as yet a wellbeing issue to urge general society to genuinely follow these suggested preventive activities. Individuals' risk view of a pandemic is one of the variables adding to an increment in public interest in embracing preventive measures (Cowling, Liao, Lam, and Wu2010).

It is worthy of note likewise that the direction of an irresistible sickness spread is regularly influenced by the conduct of people, and the conduct is regularly identified with people's hazard recognition (Zhang, Wang, Zhu, 2020). Despite the fact that there is generally high information on COVID-19 
among Nigerians (Olapegba, Iorfa and Kolawole 2020), there is the likelihood that the mistaken assumptions might be making light of preparatory conduct among Nigerians. The expectation of the overall population to embrace defensive measures is fundamentally affected by significant levels of apparent hazard. The public view of the seriousness/severity to a specific health danger determines people's risk perception about a sickness. Accordingly, during a pandemic, getting data from different sources, for example, general health experts, the media, and the authorities can expand individuals' awareness about the hazard, and thus, their selection of preventive measures (van der Weerd, Timmermans, Beaujean, Oudhoff, Beaujea, and van Steenbergen 2011). It has become necessary to introduce holistic measures in promoting COVID-19 awareness among the populace, all hands must be on deck to resolve or find a solution to the spread of the virus. Since people's opinion about the reality and severity of a pandemic is generated through their perception and knowledge of the pandemic in their cognition, it is expedient to administer psychological measures in addressing possible internalized negligent and nonchalant attitudes serving as risk behaviour to the spread of the virus. Upon this consideration, one psychological measure that may become useful in resolving the wrong beliefs, as well as inattention to the seriousness of the virus towards the promotion of the disease awareness and precautionary measures is the cognitive reframing therapy.

Cognitive reframing therapy has been utilized to portray the schematic change mechanism enunciated in cognitive therapy. According to Dobson and Dozois (2010), it alludes to an organized, shared helpful approach in which upset people are instructed on how to distinguish, assess, and alter the defective thoughts, perceptions, and convictions that are considered responsible for their psychological and behavioural maladjustment. In their original treatment manual, Beck and partners accentuated thought selfmonitoring, external retribution, reality testing, cost/benefit analysis, evidence gathering, examining consequences, behavioral assessment, and generating alternatives, as key mediations for initiating intellectual change (Beck et al., 1979).A key objective of cognitive reframing is to turn around these maladaptive thoughts which serve as precipitation to abnormal behaviours and empowering absorption of more versatile, healthy, and realistic thoughts.

Customarily, an adjustment in conviction evaluations is viewed as a proportion of the client's progression from maladaptive reasoning to more typical, versatile helpful thoughts (Beck et al., 1979). It is a common knowledge that people's manifested behaviours be it healthy or unhealthy is a product of their reasoning and psychological functioning, therefore, inattention, procrastination and other unhealthy behaviour as regards COVID-19 prevention might have also resulted from faulty thinking, an idea which developed into the adoption of this therapeutic measure for the promotion of COVID-19 awareness. The cognitive reframing therapy has been generally explored and has been found effective while treating challenges such as anxiety, depression, and selfesteem (Morton, et al., 2012), Obsessive-compulsive disorder (Jonsson et al., 2011), substance misuse and survivors of trauma and abuse (Ruffolo and Fischer, 2009) amongst others. Another measure that has been popularly used to promoting health behaviours is motivational interviewing.

Motivational interviewing (MI) is a counseling technique that improves inspiration through the goal of indecision/ambivalence. The remedial measure came out of the Prochaska and DiClemente model (Prochaska, and DiClemente 1986).Motivational interviewing is supported by a progression of rules that accentuate a collaborative therapeutic relationship where the autonomy of the patient is regarded and the patient's innate assets for change are promoted by the therapist. In motivational interviewing, the therapist is seen as a facilitator as opposed to master, who embraces a non-confrontational way to deal with the patient toward change. The general motive of MI has been portrayed as community oriented, suggestive and respecting of patient autonomy (Miller and Rollnick2002). Miller and Rollnick (2002)also remarked that the utilization of MI framework without the motive of MI is insufficient. Albeit, the MI approach is viable at helping the obviously 'unmotivated' people and when considered with regards to standard practice can be an amazing commitment procedure.

Motivational interviewing has been found effective in the treatment of health behavioural problems(Burke, Arkowitz, and Dunn, 2002). Smith et al (1997) examined the adequacy of motivational interviewing on the promotion of physical movement and dietary on overweight dark American ladies. The result of the intervention returned effective, promoting good dietary behaviour among the study subjects. On the effective of motivational interviewing on primary health and prevention, Harland et al. (1999) study enlisted 523 general clinical practice patients to assess the viability of MI in advancing physical action. The sample comprised of sedentary but healthy lower-income adults 40-64 years old. After the post-test measures the study revealed effectiveness of the therapy in reducing sedentary lifestyle amongst the sample, thereby promoting a healthy living. In the light of these observations, the effectiveness of these aforementioned psychotherapies (cognitive reframing therapy and motivational interviewing) in promoting COVID-19 pandemic awareness and precautionary behaviours will be investigated.

COVID-19 pandemic is a global challenge that has claimed many lives around the world. The onset of the virus prompted a significant level of anxiety, helpful in preventing the spread of the disease through the use of face mask, hand washing and sanitizing, social distancing, keeping to lockdown regulations amongst other measures. But as time goes on, people are becoming sentimental to the precautionary measures laid down by the authorities and health officials, some people are reportedly tired of social distancing as it limits their day to day social lifestyle. A lot of people have dismissed the directive of simple preventive measures, getting exposed to 
the virus and unknowingly spreading it especially those who are asymptomatic. People are becoming reluctant and carefree, refusing to adjust to the new normal, and yet contacts with the virus are being recorded on a daily basis, while some are dying as a result of the complications. This envisaged problem needs a solution. There is a cogent need to enhance the health-behaviours as regards the virus.

\section{Purpose of the Study}

The aim of this research is to evacuate the effectiveness of Cognitive Reframing Therapy and Motivational Interviewing on the promotion of COVID-19 awareness and health behaviours among Ibadan people. More specifically, the sole objectives of this study are:

i. To find out the effectiveness of cognitive reframing therapy on the promotion of COVID-19 awareness and health-behaviours in Ibadan

ii. To find out the effectiveness of motivational interviewing on the promotion of COVID-19 awareness in Ibadan.

iii. To find out the differential effectiveness of cognitive reframing therapy and motivational interviewing on the promotion of COVID-19 awareness and healthbehaviours in Ibadan

iv. To examine the differential effectiveness of cognitive reframing therapy on the promotion ofCOVID-19 awareness and health-behaviours of male and female in Ibadan

v. To examine the differential effectiveness of motivational interviewing on the promotion ofCOVID-19 awareness and health-behaviours of male and female in Ibadan

\section{Research Hypotheses}

The following null hypotheses will be tested at 0.05 level of significance

i. There is no significant effectiveness of cognitive reframing therapy on the promotion of COVID-19 awareness and health-behaviours in Ibadan

ii. There is no significant effectiveness of motivational interviewing on the promotion of COVID-19 awareness and health-behaviours in Ibadan

iii. There is no significant differential effectiveness of cognitive reframing therapy and motivational interviewing on the promotion of COVID-19 awareness and health-behaviours in Ibadan

iv. There is no significant differential effectiveness of cognitive reframing therapy on the promotion of COVID-19 awareness and health-behaviours of male and female in Ibadan

v. There is no significant differential effectiveness of motivational interviewing on the promotion of COVID-19 awareness and health-behaviours of male and female in Ibadan

$$
\text { i. }
$$

\section{METHODOLOGY}

\section{Research Design}

This study made use of Quasi-experiment which included pretest, post-test and control group. Quasi experiment design is known to establish cause and affect relationships among variables. This design is found suitable for this study because of its ability to manipulate variables. In this study, the researcher under certain control conditions manipulated two independent variables (cognitive reframing therapy and motivational interviewing) and observed their effectiveness on the promotion of COVID-19 awareness and health-behaviours of male and female residents in Ibadan.

The quasi-experimental design is represented below:

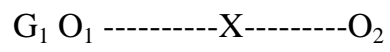

$\mathrm{G}_{2} \mathrm{O}_{3}---------\mathrm{X}--------\mathrm{O}_{4}$

$\mathrm{G}_{3} \mathrm{O}_{5}$

Therapy)

$$
\mathrm{G}_{1}=\text { Experimental Group } 1 \text { (Cognitive Reframing }
$$

$$
\mathrm{G}_{2}=\text { Experimental Group } 2 \text { (Motivational }
$$

Interviewing)

$$
\begin{aligned}
& \mathrm{G}_{3}=\text { Control group } \\
& \mathrm{O}_{1}=\text { Pre-test (Cognitive Reframing Therapy) } \\
& \mathrm{X}=\text { Treatment } \\
& \mathrm{O}_{2}=\text { Post-test (Cognitive Reframing Therapy) } \\
& \mathrm{O}_{3}=\text { Pre-test (Motivational Interviewing) } \\
& \mathrm{O}_{4}=\text { Post-test (Motivational Interviewing) } \\
& \mathrm{O}_{5}=\text { Pre-test (Control group) } \\
& \mathrm{O}_{6}=\text { Post-test (Control group) }
\end{aligned}
$$

\section{Population of the Study}

The population of this study essentially consisted ofCOVID19 prevention negligent individuals in Ibadan, who were scientifically observed to neglect the reality of the COVID-19 pandemic i.e. people who do not take proper precautionary measures against a contact with the virus. Ibadan has eleven local government areas: Ibadan North, Ibadan North-East, Ibadan North-West, Ibadan South-East, Ibadan South-West, Akinyele, Egbeda, Ido, Lagelu, OnaAra and Oluyole local government areas. Three local governments were systematically selected to represent the entire population.

\section{Sample and Sampling Technique}

The sample size for this study comprised sixty (60) participants. The participants were selected using multistage sampling procedure which is explained as follow:

Stage 1: The Hat method of the Simple Radom Sampling technique was utilized to select three (3) local governments in Ibadan which are Ibadan North East, Egbeda and Akinyele 
local government areas. The rationale for the choice of the simple randomization procedure was to avoid possible biases in the selection process.

Stage 2: The ballot type simple random sampling technique was engaged in selecting one (1) ward in each of the selected local government areas making a total of three (3) wards.

Stage 3: The same simple randomization technique was employed to select fifteen (15) participants from each of the selected wards after they were screened as COVID-19 prevention negligent individuals making a total of sixty (60) participants. Each of the twenty (20) participants randomly selected were duly engaged in each of the study groups (i.e. 20to Cognitive Reframing Therapy and 20 to Motivational Interviewing) and the other twenty (20) to the control group.

\section{Inclusion Criteria}

Each of the study participants were required to satisfy the following conditions for inclusion in the study:

i. Participants must be willing to be included without any form of coercion

ii. Participants must sign a consent form before participating in the study

iii. Participants must have scientifically observed and found negligent to COVID-19 preventions

\section{Instrumentation}

The instrument used for this study to gather pre-test and posttest data from the field was a questionnaire. The questionnaire was a standardized instrument; it was modified to commensurate the objectives and hypotheses of the study. The instrument was a self-report questionnaire developed by AlHanawi, Angawi, Alshareef, Ameerah et al (2020) designed to evaluate knowledge and attitudes towards COVID-19. Details of the instrument are given below

\section{Demographic Characteristics of the Respondents}

The demographic section included variables like gender and age. These variables were provided with various alternate objectives to which participants were allowed to choose just one answer as applicable to them.

\section{Instrumentation}

A self-report questionnaire on COVID-19 knowledge and adherence to safety measures developed by Hanawi, Angawi, Alshareef, Ameerah et al (2020) was used to collect pre and post-test measures for the study. The instrument was designed by the authors on four factors which include demographic information, knowledge of COVID-19 (i.e. modes of transmission, clinical symptoms, treatment, risk groups, isolation, prevention and control) (22 items), attitudes towards COVID-19 (6 items) and practices and Behaviours (5 items). The instrument was adapted on a five-point Likert response format ranging from Strongly Agree to Strongly Disagree. The authors reported the internal consistency for the instrument to range from .70 to .81 . For the purpose of revalidating the instrument to determine its suitability for localization, the instrument was tested on 20 people (not part of the main study), using the split half internal consistency reliability method, the instrument yielded .78.

\section{Procedure for Administration}

The study is designed to be carried out in stages: pre-session activities, pre-test, treatment and post-test. The pre-session activities included recruiting of participants in the experimental and control group. A letter of introduction was given obtained from the Dean's office, Faculty of Social Sciences was served to the study participants to educate them on the intentions of the study and seek their sufficient support in the process of the study. Considering the COVID-19 physical distancing policy, appropriate arrangements were made for the space where the treatments took place.

The researcher engaged the participants for one hour in a week for six weeks. Prior to the treatments, adequate consultations were made to familiarize self with the participants and solicit the participants' willingness to participate in the study.

At the pre-test stage, questionnaire on COVID-19 knowledge and attitude was administered to the participants. The first experimental group (A1) was treated using Cognitive Reframing Therapy; the second experimental group (A2) was treated using Motivational Interviewing. These groups were subjected to six weeks training and the treatment commenced a week after the pre-treatment measure. While the participants in the two experimental groups were engaged for six weeks of cognitive reframing therapy and motivational interviewing, each session lasted for 60 minutes interaction with the participants.

However, participants in the control group were not treated but they were limitedly educated on the knowledge of COVID-19. The post test was also administered to the control group after the end of the treatment sessions on the treatment groups.

\section{Ethical Issues}

Participation in the study was voluntary; each participant was given a consent form which obtained their consent for participation in the study. In addition to the consent form, anonymity of the study participants and confidentiality of information was guaranteed. The instruments did not include the participant's personal information; instead, the use of codes was adopted.

\section{SUMMARY OF TREATMENT PROCEDURE}

\section{Treatment/Experimental Group 1: Cognitive Reframing Therapy}

Cognitive reframing therapy remains a popular approach which focuses on the changes in people's line of thoughts and how they interpret events, especially for individuals with distorted thoughts. In CRT, distorted thoughts are desensitized 
systematically and new and healthy patterns of thinking introduced.

\section{Treatment Goal}

The main objective of this treatment procedure was to educate/enlighten the participants on how their irrational/distorted thoughts about the pandemic affected their responses to precautionary methods and exposed them to danger of contacting the virus. The treatment was designed to sensitize reasonable patterns of thinking towards good adherence to COVID-19 instructions.

Session 1: Orientation to the programme/administration of Pre-test measures

Session 2: Identification of Automatic Thoughts and believes about the virus

Session 3: Noting of Distorted Thoughts in the Automatic Thoughts

Session 4: Logical Altercation of Automatic Thoughts

Session 5: Development of Logical Contradiction to the Automatic Thoughts

Session 6: Overall Review and Administration of Post-test Measures

\section{Experimental Group 2: Motivational Interviewing}

Motivational interviewing is a technique that enables individuals to make behavioural changes critical for life development. The therapeutic measure motivates individuals towards making adequate changes in their lives by developing their self-efficacy. The general goal of MI is to build and strengthen individual's potential/internal motivation towards helping them identify change goals and manifesting the goals.

\section{Treatment Goal}

The aim of this treatment was to promote the reality of COVID-19, motivate participants towards a behavioural change that will help them to prevent themselves from contacting COVID-19. The treatment also aimed at boosting participants' self-efficacy in order to help them develop confidence in their ability to prevent the virus.

Session 1: Orientation to the programme/administration of Pre-test Measures

Session 2: Evaluation of believes about the virus and expression of empathy on participants' motivation for COVID-19 awareness and health-behaviours

Session 3: Developing discrepancies participants attitudes

Session 4: Addressing participants ambivalence through the rolling with resistance principle

Session 5: Promotion of Self Efficacy

Session 6: Participants discussions and professional clarifications
Session 7: Overall Review and Administration of Post-test Measures

\subsubsection{Control of Extraneous Variables}

The researcher guided against the effect of extraneous variables by strictly adhering to the following measures:

1. Adhered to the specified inclusion criteria

2. Researcher made sure participants were randomized into the two experimental/intervention groups

3. Strictly Adhered to $3 \times 2 \times 3$ factorial matrix

4. Adopted Analysis of Covariance (ANCOVA) statistical tool

\subsection{Method of Data Analysis}

Data collected from the field were analyzed using descriptive and inferential statistics. The descriptive statistics of numbers and simple percentage table was used to analyze the demographic data. The Analysis of Covariance (ANCOVA) was used to test the all hypothesis.

\section{RESULTS}

\section{Introduction}

The analysis of the data collected from participants is presented in this chapter. The Demographic information was analyzed using the descriptive statistics of frequency count and percentage table. Five null hypotheses were tested using the one-way analysis of covariance at 0.05 level of significance. The results of the findings go thus:

\section{Demographic Data}

The data obtained from the field covers the distribution of respondents into the two experimental groups and one control group. The distribution of respondents by gender was also presented in this section:

Table 4.1: Distribution of respondents in the two experimental groups and one control group

\begin{tabular}{|c|c|c|}
\hline Groups & Number & Percentage \\
\hline $\begin{array}{c}\text { Cognitive } \\
\text { Reframing } \\
\text { Therapy }\end{array}$ & 20 & $33 \%$ \\
\hline $\begin{array}{c}\text { Motivational } \\
\text { Interviewing }\end{array}$ & 20 & $33 \%$ \\
\hline Control & 20 & $33 \%$ \\
\hline Total & 60 & $100 \%$ \\
\hline
\end{tabular}

Table 4.1 revealed the distribution of respondents in three groups. The treatment/experimental groups on cognitive reframing and motivational interviewing consisted of twenty (20) participants each, representing 33\% respectively. Also, the third group (control) also had 20 participants which also represented $33 \%$ of the participants. 
Table 4.2: Distribution of respondents by gender

\begin{tabular}{|c|c|c|}
\hline Groups & Number & Percentage \\
\hline Male & 41 & $68.33 \%$ \\
\hline Female & 19 & $31.67 \%$ \\
\hline Total & 60 & $100 \%$ \\
\hline
\end{tabular}

Table 4.2 above reveals the distribution of participants by gender from the experimental groups and control group. Male participants comprised $41(68.33 \%)$ while female respondents were $19(31.67 \%)$. This finding implies that the majority of participants in the study were males.

\section{Hypotheses Testing}

This section presents the findings of the hypothesis after being tested using one-way analysis of covariance. The following subsection details the findings on each of the hypothesis.

Hypothesis one: There is no significant effectiveness of cognitive reframing therapy on the promotion of COVID-19 awareness and health-behaviours in Ibadan

Table 4.3 One-way Analysis of Covariance on Effectiveness of Cognitive Reframing Therapy against the Control Group

$\mathrm{R}$ squared $=.973$ (Adjusted $\mathrm{R}$ squared $=.971)$

\begin{tabular}{|c|c|c|c|c|c|}
\hline Source & $\begin{array}{c}\text { Type } \\
\text { Three } \\
\text { Sum of } \\
\text { Squares }\end{array}$ & Df & $\begin{array}{c}\text { Mean } \\
\text { Square }\end{array}$ & F & Sig \\
\hline $\begin{array}{c}\text { Corrected } \\
\text { Model }\end{array}$ & $5043.488^{\mathrm{a}}$ & 2 & 2654.868 & 316.124 & .000 \\
\hline Intercept & 488.310 & 1 & 488.310 & 65.248 & .000 \\
\hline Pretest & 2,546 & 1 & 2,546 & .364 & .495 \\
\hline Group & 4885.216 & 1 & 4885.216 & 742.196 & .000 \\
\hline Error & 182.266 & 26 & 6.248 & & \\
\hline Total & 92401.000 & 32 & & & \\
\hline $\begin{array}{c}\text { Corrected } \\
\text { Total }\end{array}$ & 5465.288 & 28 & & & \\
\hline
\end{tabular}

Table 4.3 above reveals a one-way analysis of covariance conducted to assess the effectiveness of cognitive reframing therapy on the promotion of COVID-19 awareness and healthbehaviours among residents of Ibadan when compared to control group on post treatment scores, $F=742.196, p=.000$. The finding also reveals that $97.3 \%$ of variance in post-test score can be illustrated by the treatment. It is logical to hence deduct that to a significant extent, cognitive reframing therapy was effective in promotingCOVID-19 awareness and healthbehaviours of participants. Hence, the null hypothesis directed at no significant effectiveness of cognitive reframing therapy on the promotion of COVID-19 awareness and healthbehaviours was rejected.

Hypothesis two: There is no significant effectiveness of motivational interviewing on the promotion of COVID-19 awareness and health-behaviours in Ibadan
Table 4.4 One-way Analysis of Covariance on Effectiveness of Motivational Interviewing against the Control Group

\begin{tabular}{|c|c|c|c|c|c|}
\hline Source & $\begin{array}{c}\text { Type } \\
\text { Three } \\
\text { Sum of } \\
\text { Squares }\end{array}$ & Df & $\begin{array}{c}\text { Mean } \\
\text { Square }\end{array}$ & F & Sig \\
\hline $\begin{array}{c}\text { Corrected } \\
\text { Model }\end{array}$ & $5061.546^{\mathrm{a}}$ & 2 & 2733.754 & 323.317 & .000 \\
\hline Intercept & 421.524 & 1 & 421.524 & 48.335 & .000 \\
\hline Pretest & 1,764 & 1 & 1,764 & .276 & .662 \\
\hline Group & 4985.535 & 1 & 4985.535 & 657.327 & .000 \\
\hline Error & 232.363 & 26 & 7.537 & & \\
\hline Total & 92868.000 & 32 & & & \\
\hline $\begin{array}{c}\text { Corrected } \\
\text { Total }\end{array}$ & 5658.327 & 28 & & & \\
\hline
\end{tabular}

a. $\mathrm{R}$ squared $=.968($ Adjusted $\mathrm{R}$ squared $=.967)$

Table 4.4 above shows a one-way analysis of covariance conducted to assess the effectiveness of motivational interviewing on the promotion of COVID-19 awareness and health-behaviours among residents of Ibadan when compared to control group on post treatment scores, $F=657.327, p=$ .000 . The finding also reveals that $96.8 \%$ of variance in posttest score can be explicated by the treatment. It is logical to assert that to a significant extent, motivational interviewing was effective in promotingCOVID-19 awareness and healthbehaviours of participants. Therefore, the null hypothesis focused at no significant effectiveness of motivational interviewing on the promotion of COVID-19 awareness and health-behaviours was rejected

Hypothesis three: There is no significant differential effectiveness of cognitive reframing therapy and motivational interviewing on the promotion of COVID-19 awareness and health-behaviours in Ibadan

Table 4.5 One-way Analysis of Covariance on the differential effectiveness of cognitive reframing therapy and motivational interviewing

\begin{tabular}{|c|c|c|c|c|c|}
\hline Source & $\begin{array}{c}\text { Type Three } \\
\text { Sum of } \\
\text { Squares }\end{array}$ & Df & $\begin{array}{c}\text { Mean } \\
\text { Square }\end{array}$ & F & Sig \\
\hline Corrected Model & $3.746^{\mathrm{a}}$ & 2 & 2.627 & .292 & .000 \\
\hline Intercept & 406.792 & 1 & 406.792 & 44.463 & .000 \\
\hline Pretest & 2,542 & 1 & 2,542 & .534 & .581 \\
\hline Group & .762 & 1 & .762 & .098 & .821 \\
\hline Error & 228.625 & 2 & 7.801 & & \\
\hline Total & 129728.000 & 32 & & & \\
\hline Corrected Total & 629.482 & 28 & & & \\
\hline
\end{tabular}

a. $\quad$ R squared $=.19($ Adjusted $\mathrm{R}$ squared $=.062)$

Table 4.5 above illustrates a one-way analysis of covariance conducted to test the differential effectiveness of cognitive reframing therapy and motivational interviewing on the promotion of COVID-19 awareness and health-behaviours among residents of Ibadan. The findings revealed that there was no significant differential effectiveness of cognitive 
reframing therapy and motivational interviewing on the promotion of COVID-19 awareness and health-behaviours of participants, $F=.098, p=0.821$. The finding also indicated that $2.9 \%$ of the variance in the post-test score can be explained to the group. It can therefore be opined to a significant extent that cognitive reframing therapy and motivational interviewing were equally effective in promoting COVID-19 awareness and health-behaviours of participants. By implication, the null hypothesis that states that there is no significant differential effectiveness of cognitive reframing therapy and motivational interviewing on the promotion of COVID-19 awareness and health-behaviours is therefore retained.

Hypothesis four: There is no significant differential effectiveness of cognitive reframing therapy on the promotion of COVID-19 awareness and health-behaviours of male and female in Ibadan

Table 4.6 One-way Analysis of Covariance on the differential effectiveness of cognitive reframing therapy on the promotion of COVID-19 awareness and health-behaviours of male and female participants

\begin{tabular}{|c|c|c|c|c|c|}
\hline Source & $\begin{array}{c}\text { Type } \\
\text { Three } \\
\text { Sum of } \\
\text { Squares }\end{array}$ & Df & $\begin{array}{c}\text { Mean } \\
\text { Square }\end{array}$ & F & Sig \\
\hline $\begin{array}{c}\text { Corrected } \\
\text { Model }\end{array}$ & $8.454^{\mathrm{a}}$ & 2 & 3.988 & .806 & .592 \\
\hline Intercept & 189.548 & 1 & 189.548 & 32.794 & .000 \\
\hline Pretest & 3,763 & 1 & 3,763 & .461 & .546 \\
\hline Gender & 5.942 & 1 & 5.942 & .924 & .379 \\
\hline Error & 81.747 & 14 & 7.782 & & \\
\hline Total & 69224.000 & 18 & & & \\
\hline $\begin{array}{c}\text { Corrected } \\
\text { Total }\end{array}$ & 91.200 & 16 & & & \\
\hline
\end{tabular}

a. $\mathrm{R}$ squared $=.094$ (Adjusted $\mathrm{R}$ squared $=.059$ )

Table 4.6 above shows a one-way analysis of covariance conducted to test the differential effectiveness of cognitive reframing therapy in promoting COVID-19 awareness and health-behaviours among male and female participants. In this finding, the covariate utilized was the pre-test score of both male and female exposed to cognitive reframing therapy. After adjusting the covariate, the finding reveals no significant differential effectiveness of cognitive reframing therapy on the promotion of COVID-19 awareness and health-behaviours of male and female participants, $F=.924, p=0.379$. The finding also indicates that only $9.4 \%$ of variance in the posttest score can be attributed to the gender. This illustrates that the effectiveness of the therapy on the promotion ofCOVID19 awareness and health-behaviours of male and female participants was equal. Hence, the hypothesis that states that there is no significant differential effectiveness of cognitive reframing therapy on the promotion ofCOVID-19 awareness and health-behaviours of male and female participants is retained.
Hypothesis five: There is no significant differential effectiveness of motivational interviewing on the promotion of COVID-19 awareness and health-behaviours of male and female in Ibadan

Table 4.7 One-way Analysis of Covariance on the differential effectiveness of motivational interviewing on the promotion of COVID-19 awareness and health-behaviours of male and female participants

a. $\quad \mathrm{R}$ squared $=.174($ Adjusted $\mathrm{R}$ squared $=.031)$

\begin{tabular}{|c|c|c|c|c|c|}
\hline Source & $\begin{array}{c}\text { Type } \\
\text { Three } \\
\text { Sum of } \\
\text { Squares }\end{array}$ & Df & $\begin{array}{c}\text { Mean } \\
\text { Square }\end{array}$ & F & Sig \\
\hline $\begin{array}{c}\text { Corrected } \\
\text { Model }\end{array}$ & $21.236^{\mathrm{a}}$ & 2 & 9.974 & 1.846 & .398 \\
\hline Intercept & 197.302 & 1 & 197.302 & 22.763 & .002 \\
\hline Pretest & 5,874 & 1 & 5,874 & .862 & .488 \\
\hline Gender & 6.679 & 1 & 6.679 & .948 & .391 \\
\hline Error & 100.594 & 14 & 8.770 & & \\
\hline Total & 71535.000 & 18 & & & \\
\hline $\begin{array}{c}\text { Corrected } \\
\text { Total }\end{array}$ & 121.102 & 16 & & & \\
\hline
\end{tabular}

Table 4.7 above shows a one-way analysis of covariance conducted to test the differential effectiveness of motivational interviewing on the promotion of COVID-19 awareness and health-behaviours among male and female residents of Ibadan. In this finding, the covariate utilized was the pre-test score of both male and female exposed to motivational interviewing. After making appropriate adjustment to the covariate, the finding reveals no significant differential effectiveness of motivational interviewing on the promotion ofCOVID-19 awareness and health-behaviours of male and female participants, $F=.948, p=0.391$. The finding also indicates that only $17.4 \%$ of variance in the post-test score can be attributed to the gender. This illustrates that the effectiveness of the therapy on the promotion of COVID-19 awareness and health-behaviours of male and female participants were equal. Hence, the hypothesis that states that there is no significant differential effectiveness of motivational interviewing on the promotion of COVID-19 awareness and health-behaviours of male and female participants is retained.

\section{SUMMARY OF MAJOR FINDINGS}

The findings of the study revealed that:

1. Cognitive reframing therapy was effective in promoting COVID-19 awareness and healthbehaviours of participants in Ibadan $(F=742.196, p$ $=0.000)$. This alludes that the mean of COVID-19 awareness and health-behaviours after exposure to cognitive reframing therapy significantly improved.

2. Motivational interviewing was effective in promoting COVID-19 awareness and health-behaviours of participants in Ibadan $(\mathrm{F}=657.327, \mathrm{p}=0.000)$. This means that the mean of COVID-19 awareness and 
health-behaviours after exposure to motivational interviewing significantly improved.

3. In comparing both techniques, significant differential effects do not exist between cognitive reframing therapy and motivational interviewing in their effectiveness in promoting COVID-19 awareness and health-behaviours of participants in Ibadan $(\mathrm{F}=.098$, $\mathrm{p}=0.821$ ). This is as a result of participantsCOVID19 awareness and health-behaviours mean scores after exposure to both therapeutic measures significantly improved.

4. Significant difference was not found to exist between the COVID-19 awareness and health-behaviours of male and female participants exposed to cognitive reframing therapy $(\mathrm{F}=.924, \mathrm{p}=0.379)$. This is because both genderCOVID-19 awareness and health-behaviours mean scores were significantly improved.

5. Significant difference was not found to exist between the COVID-19 awareness and health-behaviours of male and female participants exposed to motivational interviewing $(\mathrm{F}=.948, \mathrm{p}=0.391)$. This is because both gender COVID-19 awareness and healthbehaviours mean scores were significantly improved.

\section{DISCUSSION, CONCLUSION AND RECOMMENDATION}

\section{Discussion}

The findings of this study revealed that there was a significant effect of cognitive reframing therapy on the promotion of COVID-19 awareness and health-behaviours of Ibadan residents. This, the null hypothesis is rejected. The possible rationale for this finding is that residents are becoming skeptical about the existence and reality of the virus. A lot of people believe that the spread of the virus is not as significant as it is painted, some dismissed the importance of precautionary measures because they can not really identify with someone who is positive to the virus or severely ill as a result of the virus. Some believe the government has decided to deceive the public and embezzle public funds on the account of the virus spreading unrealistic data, while some simply hold that the virus is significant to the executives and the well to do people alone. All these faulty thought patterns serve as strain to the people's adjustment to the new normal. Therefore, because of the strength of cognitive reframing therapy in identifying faulty thoughts and sensitizing healthy thought patterns, the finding is rationalized.

This finding is corroborated with the study of Ramsay (2008) which investigated the effectiveness of cognitive reframing therapy on the treatment of procrastination. The result of the study proved effective. Likewise, the study of Solanto (2010) studied the effectiveness of cognitive reframing therapy and supportive therapy in the management of inattention, the study found a significant effect of cognitive reframing therapy in reducing attention deficit.
The findings of this study also revealed a significant effect of motivational interviewing on cognitive reframing therapy on the promotion of COVID-19 awareness and healthbehaviours. Hence, the null hypothesis is rejected. It is not a gainsaying that most times people need an eye-opener in motivating them towards a behaviour. Behaviours are often learned and it has been declared that every learned behaviour can be unlearned through effective resources. A motivational relationship takes a long way in insulating helpful behaviours, some people are even unaware of their capacity to carry out a given task until they get motivated and by making them realize their hidden potential and ability to undergo a given task. More specifically to the population of this study, the majority are less educated individuals who often dismiss sensitive information due to their little or no exposure to formal education, hence, when they get close to a more educated fellow or a specialist, in a therapeutic relationship, who can expose their weaknesses, and inspire their potentials, they adjust. For these reasons, the outcome of this finding is justified.

This finding is in line with the study of Harland et al. (1999) which investigated the effect of motivational interviewing in reducing sedentary lifestyle and the promotion of healthy physical behaviours. The study enlisted 523 hospital patients to assess the viability of MI in advancing physical action. The study revealed the effectiveness of the therapy in advancing the physical lifestyle of the study sample.

The findings of this study reveal that there is no significant differential effectiveness of cognitive reframing therapy and motivational interviewing on the promotion of COVID-19 awareness and health-behaviours in Ibadan. In other words, both therapies revealed equal effectiveness in the promotion of COVID-19 awareness and health-behaviours of the participants. The null hypothesis was therefore retained. Both therapies are behavioural change measures with different components but also similar in characteristics such as identification of individual differences, fostering of potentials and self-efficacy towards adjustment and acceptance of new behaviour, perhaps these aforementioned reasons may account for this finding. The study also revealed that there is no significant differential effect of both cognitive reframing therapy and motivational interviewing on the promotion of COVID-19 awareness and health-behaviours of male and female participants. In other words, both therapies equally proved effective in the promotion of COVID-19 awareness and health-behaviours which calls for the retainment of the null hypotheses. Since the therapeutic relationship was administered in groups, no individual or gender considerations were made in the process, all participants were equally treated in groups which combined both genders, there was no individual or gender consideration of any kind, this might have accounted for this finding. This also implies that both genders accepted the therapeutic relationship equally and thus, the equal result was attained. 
This finding is bolstered by the study of Calbring et al (2009) which compared CBT and motivational interviewing in the treatment of pathological gambling. The study comprised 150 participants experiencing gambling problems after screening with the NORC DSM-IV screen for gambling problems. The samples were randomized to four different individual sessions of MI, and eight sessions of cognitive-behavioural therapy. The study revealed no differential effectiveness of the therapies in the treatment of pathological gambling behaviour as both measures equally proved effective. Also, the study of Riper et al (2014) studied CBT and motivational interviewing for comorbid alcohol use disorder. The study summarily found the effectiveness of both therapies in the management of the challenge.

\section{Recommendation}

In line with the findings of this study, the following are therefore recommended:

- The government, health authorities, and nongovernmental organizations advocating public health should endeavor to engage the public in closer means. Representatives can be engaged in a large form (taking cognizance to thee precautionary measures), meeting people from one community to another, sensitizing them on the spread of the virus, and most importantly getting feedback from them so as to clear their doubts and anxiety about the virus. Each local government should have health representatives who will be saddled with the responsibility of communing with subjects, evaluation of matters arising, and most importantly testing people on the virus for good control, management, and prevention of the spread of the virus.

- There is a need to urgently mobilize and structure psychological health facilities in the midst of the populace to adequately manage their psychological well being towards the prevention of the spread of the virus and the general management of psychological health. The government should endeavour to structure psychological intervention facilities supervised by certified clinical psychologists and allied professionals at local government levels where people can be referred to manage their mental health and promote their cautiousness of the virus. From the previous recommendation, representatives at local level saddled with the responsibility of public health evaluation should be trained on the identification of psychological anomalies which will enable them to refer individuals or group of individuals suspected to be mentally or psychologically vulnerable to the disease or other health implications to the specialists structured in the local government for proper management.
- In all, the authorities should endeavour to provide enough palliative to the masses, especially those who have been severely affected by lockdown policies. Though most economy is being reopened, most lockdown policies are being softened, some business has been adversely affected during the lockdown, some have shut down, and may find it extremely challenging to recover. The government should provide supervisory support in terms of capital and infrastructure to those in need in order to regain and sustain business integrity.

\section{Limitations of the Study}

In a perfect circumstance, the extent of any investigation ought to be open-ended. Because of the idea of this experimentation and circumstantial situations, limitations, and restriction policies around the COVID-19 pandemic, the extent of this investigation could not be extended beyond the limit of the researcher. To limit the complications that could result from population explosion, 60 participants were randomly selected and separated into relevant groups

\section{Suggestion for Further Study}

In light of these findings, it is hereby suggested that more examination of this study variables should be carried out across other geographical locations in the country in order to expand the generalization of the findings of this study. Also, the effectiveness of other psychological treatments/therapies should be measured on the dependent factor of this study in order to understand population differences and peculiarities as well as the appropriateness of interventions.

\section{Conclusion}

The reality of COVID-19 might be that it has come to stay as various health organizations including the WHO asserted. It may become a day to day human health challenge like Malaria, Typhoid, and HIV amongst others, life calls for compulsory adjustment. But, the impact of the virus depends on the acceptance of the realities surrounding the pandemic, adherence to preventive policies enacted by authorities, as well as tuning to the general behavioural and social adjustment needed in curbing the spread of the lifethreatening disease. Hence, everyone must take responsibility by adjusting to the "new normal", characterized by social distancing, regular hand washing, use of case mask, and exhibition of other responsible behaviours as laid down by authorities and health organizations.

\section{REFERENCES}

[1] Al-Hanawi, MK, Angawi, K, Alshareef, N, et al Knowledge, attitude and practice toward COVID-19 among the public in the Kingdom of Saudi Arabia: a cross-sectional study. Front Public Health 2020; 8: 217.

[2] Beck, A. T., Rush, A. J., Shaw, B. F., \& Emery, G. (1979). Cognitive therapy of depression. New York, NY: Guilford Press

[3] Burke, B., Arkowitz, H., \& Dunn, C. (2002). The efficacy of motivational interviewing and its adaptations: What we know so far. In W. Miller \& S. Rollnick (Eds.), Motivational interviewing: 
Preparing people for change (2nd ed., pp. 217-250). New York: Guilford Press.

[4] Cowling B. J., Ng, D. M., Ip, D. K., Liao, Q., Lam, W. W. and $\mathrm{Wu}$, J. T. (2010). Community psychological and behavioral responses through the first wave of the 2009 influenza A (H1N1) pandemic in Hong Kong. J Infect Dis. 202(6):867-76. http://doi.org/10.1086/655811 PMID: 20677945

[5] Harland, J., White, M., Drinkwater, C., Chinn, D., Farr, L., \&Howel, D. (1999). The Newcastle exercise project: A randomised controlled trial of methods to promote physical activity in primary care. British Medical Journal, 319, 828-832.

[6] Jonsson, H., Hougaard, E., \&Bennedsen, B.E. (2011). Randomized comparative study of group versus individual Cognitive Behavioural Therapy for obsessive compulsive disorder. ActaPsychiatricaScandinavica, 123, 387-397.

[7] Miller, W. R. and Rollnick, S. (2002). Motivational Interviewing. Preparing people for change. 2nd edn. New York: The Guilford Press.

[8] Olapegba, P I., Iorfa, A. K. and Kolawole, S. O. (2020). Survey data of COVID-19-related Knowledge, Risk Perceptions and Precautionary Behavior among Nigerians. Data in Brief 2020. Online first. http://www.doi.org/10.1016/j.dib.2020.105685

[9] Omopo, O. E., Dada, I. T. and Adebayo-Oke, B. (2020). Socioeconomic Status, Propaganda, Health-related Factors as Predictors of COVID-19 Pandemic-Related Psychological Distress of Lagos Residemts. International Journal of Innovative Research and Advanced Studies. 7 (7). 192-199

[10] Prochaska, J. and DiClemente, C. (1986). Towards a comprehensive model of change. In: Miller WR, Heather N, editors. Treating addictive behaviours: processes of change. New York: Pergamon.

[11] Ramsay, J. R. (2010). CBT for adult ADHD: adaptations and hypothesized mechanisms of change. Journal of Cognitive Psychotherapy;24(9):37-45.

[12] Smith, D., Heckemeyer, C., Kratt, P., \& Mason, D. (1997). Motivational interviewing to improve adherence to a behavioral weight-control program for older obese women with NIDDM. Diabetes Care, 20, 52-54

[13] Solanto, M. V, Marks, D. J., Wasserstein, J., Mitchell, K., Abikoff, H., Alvir, J. M., et al. (2010). Efficacy of meta-cognitive therapy for adult ADHD. American Journal of Psychiatry 167(8):958-68

[14] van der Weerd W, Timmermans D. R, Beaujean D. J, Oudhoff, J, van Steenbergen J. E. (2011). Monitoring the level of government trust, risk perception and intention of the general public to adopt protective measures during the influenza $A(H 1 N 1)$ pandemic in the Netherlands. BMC public health. ;11(1):575. https://doi.org/10.1186/1471-2458-11-575 PMID: 32081636 PMCID: PMC3152536 